\title{
Expression, purification and identification of Pla a1 in a codon-optimized Platanus pollen allergen
}

\author{
YUN LIU ${ }^{1}$, XIUZHEN SUN ${ }^{1}$, GUIZUO WANG $^{1}$, AILIN TAO $^{2}$, YUANYUAN WU ${ }^{1}$, \\ MANXIANG LI ${ }^{1}$, HONGYANG SHI ${ }^{1}$ and MEI XIE ${ }^{1}$ \\ ${ }^{1}$ Department of Respiratory Medicine, The Second Affiliated Hospital of Xi'an Jiaotong University, Xi'an, Shanxi 710004; \\ ${ }^{2}$ National Key Laboratory of Respiratory Diseases, Allergy Research Center, Key Laboratory of \\ Allergic Reactions and Clinical Immunology, The Second Affiliated Hospital of \\ Guangzhou Medical College, Guangzhou, Guangdong 510260, P.R. China
}

Received June 6, 2013; Accepted December 12, 2014

DOI: $10.3892 / \mathrm{mmr} .2015 .3652$

\begin{abstract}
The present study aimed to express, purify and identify the major allergen gene, Pla a1, in Platanus pollen. According to previous studies, the major gene sequences of the Pla al allergen were obtained and codon optimization and synthesis of the genome were performed using DNAStar software. Following binding of the target gene fragment and the pET-44a vector, the JM109 cells were transfected to produce positive clones. The vectors were then transformed into Escherichia coli Rosetta cells to induce the expression of the target protein. The exogenous protein was purified using affinity chromatography and was identified by western blot analysis. Pla a1, the major allergen protein in Platanus pollen, was successfully isolated and this exogenous protein was purified using affinity chromatography. The present study was the first, to the best of our knowledge, to obtain expression of the allergen recombinant protein, Pla a1, fused with a Strep-TagII via codon optimization and provided the basis for the preparation of allergens with high purity, recombinant hypoallergenic allergens and allergen nucleic acid vaccines.
\end{abstract}

\section{Introduction}

Platanus belongs to the family Platanaceae and grows in a wide distribution. Kosisky et al (1) investigated airborne pollen allergens between 1998 and 2007 by quantitative collection in downtown Washington, WA, USA and the results demonstrated that the major pollen types include oak, cypress, Pinaceae, Morus, Betulaceae, Acer, Platanus,

Correspondence to: Dr Xiuzhen Sun, Department of Respiratory Medicine, The Second Affiliated Hospital of Xi'an Jiaotong University, 157 Xiwu Road, Xi'an, Shanxi 710004, P.R. China E-mail: xiuzhensun@163.com

Key words: Platanus pollen, major allergen, codon optimization, expression
Fraxinus and Gramineae. Tree and grass pollens accounted for 91.2 and $7 \%$ of the total pollen count, respectively. Aira et al (2) demonstrated that Platanus and Olea are important local sources of pollen in Iberian Peninsula, located in the northwest of Spain. Ture et al (3) reported that Bilecik Pinus, Cupressaceae, Platanus, Quercus and Salix are the predominant types of regional airborne pollen in Turkey and the highest concentration of airborne pollen was observed in May. In northwestern Turkey, Celenk et al (4) revealed that Pinus, Olea, Platanus, Cupressaceae, Quercus, Poaceae, Urticaceae and Castanea are important in the airborne spread of pollens, of which concentrations also peaked in May. The Platanus pollen has a higher airborne concentration and also causes widespread allergy (4). Liu et al (5) investigated airborne pollen in Hubei, China, in which 2,300 patients with hay fever received skin allergen testing and seasonal incidence was analyzed. In Hubei, the pollen with the highest positive allergenic rate was Platanus in spring and Artemisia and ragweed in fall. Lu et al (6) screened 168 patients with allergic asthma for pollen blood allergens and the result suggested that mugwort, Platanus, blite, Humulus and Gramineae were the predominant allergenic pollens in Xi'an, China. Lauer et al (7) found that the allergen immunoglobulin E response rate of Platanus pollen is between 27.3 and $63.8 \%$ in the Mediterranean region and is the major regional airborne pollen allergen. A number of surveys and clinical epidemiological data have suggested that Platanus pollen is an important cause of hay fever in China and western countries (8-10).

It has been revealed that in Platanus pollen allergen extracts, Pla A1, Pla A2 and Pla A3 are the major allergenic proteins. The Pla a1 protein is detected in the serum of 92\% of patients with Platanus-induced hay fever, while the Pla a 2 and Pla a3 response rates are 84 and $63.8 \%$, respectively $(7,11,12)$. Few studies investigating the expression and purification of the major allergens in Platanus pollen have been performed. The present study successfully expressed, purified and identified the Pla a1 protein and provided the basis for preparations of allergens with high purity, recombinant hypoallergenic allergens and allergen nucleic acid vaccines. 


\section{Materials and methods}

Materials. T4 DNA ligase and a pET-44a vector were purchased from Promega Corporation (Madison, WI, USA). The host E. coli JM109 and Rosetta cells were purchased from Novagen (Darmstadt, Germany). DNA synthesis and DNA sequencing were performed by Shanghai Boshang Biological Company (Shanghai, China) and rTaq polymerase, 10X polymerase chain reaction (PCR) buffer, dNTP mixture, isopropyl $\beta$-D-1-thiogalactopyranoside (IPTG) and the DL 2,000 DNA marker were purchased from Takara Biotechnology Co. Ltd. (Dalian, China). Agarose, yeast and SYBR Green fluorescent dye were purchased from Gene Company (Chai Wan, Hong Kong). A QIAquick ${ }^{\circledR}$ PCR Purification kit and Gel Extraction kit were purchased from Qiagen (Hilden, Germany) and polyvinylidene fluoride (PVDF) membranes were purchased from Merck Millipore (Darmstadt, Germany). The prestained protein molecular weight marker was purchased from Bio-Rad Laboratories, Inc. (Hercules, CA, USA) and skim milk powder was purchased from Sigma-Aldrich (St. Louis, MO, USA). The StrepTrap ${ }^{\text {TM }}$ HP 1-ml columns were purchased from GE Healthcare Life Sciences (Shanghai, China).

Serum collection. Venous blood $(5 \mathrm{ml})$ was obtained from 18 patients (6 males and 12 females, 12-44 years old) with positive skin tests of Platanus pollen allergen at The Second Affiliated Hospital of Xi'an Jiaotong University (Xi'an, China). Following centrifugation at $2,260 \mathrm{x}$ g for $30 \mathrm{~min}$ at room temperature, the serum was obtained. The present study was approved by the Ethics Committee of The Second Affiliated Hospital of Xi'an Jiaotong University. Written informed consent was obtained from all participants.

Codon optimization and primer design. The nucleotide and amino acid sequences of PLa a1 were obtained, according to the AJ427413.2 ID number in the GenBank database (http://www.ncbi.nlm.nih.gov/genbank/). The open reading frames were 156 amino acids and 468 base pairs long. NdeI, $P s t \mathrm{I}$ and $\mathrm{Xho}$ sites and Strep-TagII were introduced during vector construction. The preferred prokaryotic expression vector of E. coli and the RNA secondary structure was considered, the initial efficiency of translation was improved and codon optimization was completed for facilitating protein translation using DNASTAR Lasergene software (version 7.1; http://wwwbioo.com/soft/ biosoft/2009/6790.html). Following codon optimization, the GC content increased between 44.3 and $47.6 \%$. The sequences of the optimized full genome were synthesized by Shanghai Boshang Biological Company.

Construction of the Pla al gene expression vector. Based on the entire coding region sequence of the optimized Pla a1 gene, a pair of primers was designed. The primers, synthesized by Shanghai Boshang Biological Company, were as follows: Forward 5'-CTCATATGGCCGATATTGTCCAGGG-3' and reverse 5'-GCCTGCAGAGCACCAAGCAGTTT-3'. The annealing temperature of the forward primer was $68.2^{\circ} \mathrm{C}$ and the reverse primer was $69.1^{\circ} \mathrm{C}$. The underlined sections highlight $N d e I$ and $P s t I$ restriction sites, respectively. The PCR amplification program was as follows: $95^{\circ} \mathrm{C}$ pre-denaturation for $5 \mathrm{~min} ; 7$ cycles of $95^{\circ} \mathrm{C}$ denaturation for $30 \mathrm{sec}, 63.3^{\circ} \mathrm{C}$ annealing for $30 \mathrm{sec}\left(1^{\circ} \mathrm{C} /\right.$ touchdown/cycle $), 72^{\circ} \mathrm{C}$ extension for $30 \mathrm{sec}, 25$ cycles of $95^{\circ} \mathrm{C}$ denaturation for $30 \mathrm{sec}, 57.3^{\circ} \mathrm{C}$ annealing for $30 \mathrm{sec}, 72^{\circ} \mathrm{C}$ extension for $30 \mathrm{sec}$ and $72^{\circ} \mathrm{C}$ extension for $5 \mathrm{~min}$. Glycerol bacteria TOP10-Puc57-pla a1 was synthesized by Gene Company and used for monoclonal colony PCR. The PCR results were detected by $1 \%$ agarose gel electrophoresis. The positive monoclonal colonies were cultured and the plasmids were extracted and double digested using $N d e \mathrm{I}$ and $P s t \mathrm{I}$ at $37^{\circ} \mathrm{C}$ for $4 \mathrm{~h}$ followed by agarose gel electrophoresis. The transformed pET44a plasmid vectors (vector containing Strep-TagII) were also double digested to obtain identical sticky ends. Following $2 \%$ agarose gel electrophoresis, the PLa a1 target fragment and the pET-44a vector were recovered and ligation was performed at a ratio of three target fragments to one vector. The T4 DNA ligases were attached to the pET44a-pla a1 recombinant plasmid at $4^{\circ} \mathrm{C}$ for $16 \mathrm{~h}$ and the ligation product was transformed into competent E. coli JM109 cells using KCM containing $0.5 \mathrm{~mol} / 1 \mathrm{KCl}, 0.15$ $\mathrm{mol} / 1 \mathrm{CaCl}_{2}$ and $0.25 \mathrm{~mol} / 1 \mathrm{MgCl}_{2}$. Following transformation, positive colonies were screened for using lysogeny broth (LB) plates (Shanghai Sangon Biological Engineering Technology and Services Co., Ltd., Shanghai, China) containing $50 \mu \mathrm{g} / \mathrm{ml}$ ampicillin (Amp) for Amp resistance. The positive clones were identified using colony PCR and were subsequently cultured at $37^{\circ} \mathrm{C}$ overnight prior to sequencing (LB liquid medium; Shanghai Boshang Biological Co., Shanghai, China). The pET44a-pla a1 plasmid was transformed into competent Rosetta cells with efficient expression and screened, as previously, for Amp resistance and PCR detection and culture for sequencing. The monoclonal colonies with the correct sequence were selected to induce protein expression.

Expression and identification of the pla al protein. The E. coli Rosetta cells containing the positive recombinant pET44a-pla a1 plasmid were inoculated in LB medium (10 g/l tryptone, $5 \mathrm{~g} / 1$ yeast extract and $10 \mathrm{~g} / 1 \mathrm{NaCl}$ ) supplemented with $50 \mathrm{mg} / \mathrm{l} \mathrm{Amp}$, at $37^{\circ} \mathrm{C}$ with agitation for $12 \mathrm{~h}$. Following incubation, the cells with $1 \%$ concentration were inoculated into fresh LB medium containing $50 \mathrm{mg} / \mathrm{l} \mathrm{Amp} \mathrm{and} \mathrm{4 \%} \mathrm{glucose}$ until the optical density (OD) at $600 \mathrm{~nm}$ reached between 0.6 and 0.7 . The OD value was determined using a 752 spectrophotometer (Nanjing Analytical Instrument Factory Co., Ltd., Nanjing, China). Subsequently, $0.5 \mathrm{mmol} / 1$ IPTG was added to induce plasmid expression $\left(4 \mathrm{~h}\right.$ at $\left.37^{\circ} \mathrm{C}\right)$. The bacteria were collected and SDS-PAGE (12\% separating gel, $4 \%$ stacking gel; Sigma-Aldrich) was used to estimate the expression of Pla a1, as described previously (13). Briefly, $1.5 \mathrm{ml}$ bacterial culture was centrifuged at $1,200 \mathrm{x}$ g for $5 \mathrm{~min}$ for collection of bacteria and $100 \mu 12 \mathrm{X}$ loading buffer containing $20 \mathrm{~g} / \mathrm{l} \mathrm{SDS}, 500 \mathrm{ml} / \mathrm{l}$ glycerol, $62.5 \mathrm{mmol} / \mathrm{l}$ Tris- $\mathrm{HCl}$ (pH 6.8), $20 \mathrm{ml} / 1 \beta$-mercaptoethanol, $0.1 \mathrm{~g} / 1$ bromophenol blue, $30 \mathrm{mmol} / \mathrm{l} \mathrm{NaCI}$ and $1 \mathrm{mmol} / \mathrm{l}$ EDTA, was added and mixed prior to boiling for $5 \mathrm{~min}$. The samples were then centrifuged at $1,200 \mathrm{x}$ g for $5 \mathrm{~min}$ and SDS-PAGE electrophoresis was performed.

Protein expression form. Protein expression was induced using the method described above. The bacterial supernatants were collected by centrifugation at $10,000 \mathrm{rpm}$ for $6 \mathrm{~min}$ at $4^{\circ} \mathrm{C}$. The bacterial wet weight was set as $5 \mathrm{ml} / 1 \mathrm{~g}$ and binding 
buffer, containing $100 \mathrm{mM}$ Tris- $\mathrm{HCl}, 150 \mathrm{mM} \mathrm{NaCl}$ and $1 \mathrm{mM}$ EDTA ( $\mathrm{pH} 8$ ), was added to resuspend the bacteria. Sonication was performed in an ice-water bath (lysis for $5 \mathrm{sec}$, termination for $5 \mathrm{sec}, 50 \%$ strength at $100 \mathrm{~W}$, lysis for $10 \mathrm{~min}$ ). The supernatant and precipitate were collected by centrifugation at $1,200 \times \mathrm{g}$ for $30 \mathrm{~min}$ at $4^{\circ} \mathrm{C}$. The precipitate was centrifuged again, as previously, and the subsequent precipitates were resuspended in binding buffer of an equal volume with $6 \mathrm{M}$ urea and agitated overnight at $4^{\circ} \mathrm{C}$. The supernatant was collected by centrifugation at $1,800 \mathrm{x} \mathrm{g}$ for $30 \mathrm{~min}$ at $4^{\circ} \mathrm{C}$ and the inclusion bodies of the expressed proteins were identified through SDS-PAGE.

Purification of the expressed Pla al protein. The denatured proteins were dialyzed for $12 \mathrm{~h}$ in binding buffer containing 4, 2 and $1 \mathrm{M}$ urea, respectively. Following dialysis, the supernatants were collected by centrifugation at $18,000 \mathrm{rpm}$ for $10 \mathrm{~min}$ at $4^{\circ} \mathrm{C}$ to prepare for protein purification. StrepTrap HP prepacked columns $(1 \mathrm{ml})$ were connected to a GE-048 AKTA FPLC system (GE Healthcare, Waukesha, WI, USA). The columns were washed using binding buffer with a $1 \mathrm{ml} / \mathrm{min}$ flow rate. The three supernatants were passed through the column and then the columns were washed using binding buffer. The penetration peaks were collected and calculated by determining the OD value using the spectrophotometer (Nanjing Analytical Instrument Factory Co., Ltd.). The columns were washed using elution buffer containing $2.5 \mathrm{mM}$ desulfurization biotin, $100 \mathrm{mM}$ Tris-HCI, $150 \mathrm{mM} \mathrm{NaCl}$ and $1 \mathrm{mM}$ EDTA (pH 8.0). The elution peaks were collected and calculated by the same method.

Western blot analysis of the purified protein. The purified fusion proteins $(15 \mu \mathrm{l})$ separated by SDS-PAGE were transferred to PVDF membranes (constant current $45 \mathrm{~mA}, 26 \mathrm{~min}$ ), prior to blocking with $50 \mathrm{~g} / 1$ skim milk dissolved in phosphate-buffered saline (PBS; Sigma-Aldrich) containing $8 \mathrm{~g} / 1 \mathrm{NaCl}$, $0.28 \mathrm{~g} / 1 \mathrm{KCl}, 0.28 \mathrm{~g} / 1 \mathrm{KH}_{2} \mathrm{PO}_{4}, 2.98 \mathrm{~g} / 1 \mathrm{Na}_{2} \mathrm{HPO}_{4} \cdot 12 \mathrm{H}_{2} \mathrm{O}$ (pH 7.4) and $1 \mathrm{ml} / 1$ Tween 20 (PBST; Sigma-Aldrich) for $2 \mathrm{~h}$ at room temperature. The membrane was then incubated with Platanus pollen allergy serum primary antibody (diluted 1:1; collected from the Respiratory Disease Laboratory of the Second Affiliated Hospital of Xi'an Jiaotong University) overnight at $4^{\circ} \mathrm{C}$. The membrane was then washed four times with PBST (5 min each) prior to incubation with horseradish peroxidase-labeled goat anti-human immunoglobulin E antibody (1:500; Shanghai Sangon Biological Engineering Technology and Services Co., Ltd.) at room temperature for $1 \mathrm{~h}$. The membrane was then washed twice with PBST (5 min each) followed by washing twice with PBS. Diaminobenzidine (Sigma-Aldrich) was used as a chromogenic substrate (10 min) to detect the antigenicity of Pla a1.

Sequencing of the purified protein. Following SDS-PAGE, the PVDF membrane was cut to an appropriate size and electroblotting was performed under $45 \mathrm{~mA}$ at room temperature for $28 \mathrm{~min}$. The membrane was stained using $0.1 \%$ Coomassie Brilliant Blue R-250 (Shanghai Sangon Biological Engineering Technology and Services Co., Ltd.) dissolved in $40 \%$ methanol $/ 1 \%$ acetic acid for $30 \mathrm{sec}$. The membrane was de-stained with $1 \%$ acetic acid and $50 \%$ methanol and

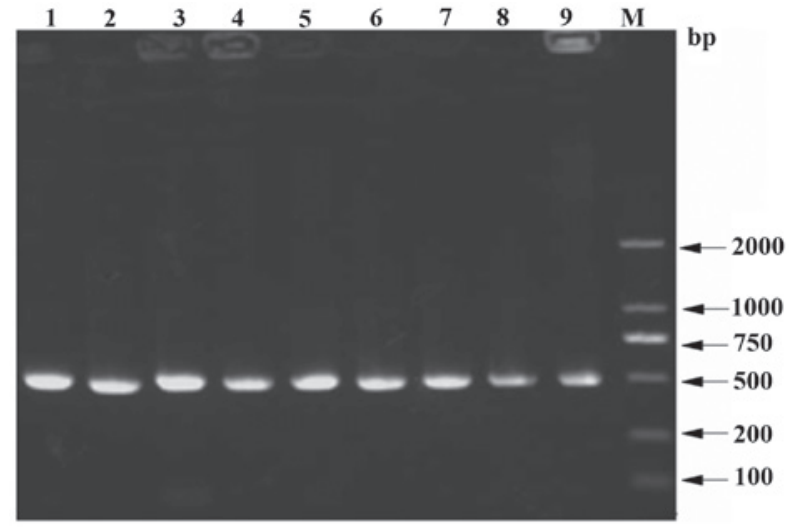

Figure 1. Electrophoresis of the JM109 colony PCR products. 1-9, the same PCR amplification product containing target fragments of $\sim 500 \mathrm{bp}$, which matched the expected fragment size. M, DL2000 DNA marker; PCR; polymerase chain reaction.

washed with deionized water. The corresponding bands were cut from the membrane and sealed in a $1.5 \mathrm{ml}$ centrifuge tube for sequencing (Proteome Research Analysis Center, Institute of Biochemistry and Cell Biology, Shanghai Institutes for Biological Sciences, Chinese Academy of Sciences, Shanghai, China).

\section{Results}

Identification of the recombinant expression vector. The recombinant vector was constructed successfully from the T7 promoter and the target fragments were identified between the NdeI and PstI restriction sites. Subsequent to the Pst I enzyme cutting site, a Strep-TagII comprising eight amino acids, a double terminal codon TAATAA and XhoI sites were observed. The PET44a-pla a1 recombinants were transferred into JM109 cells and the resistent bacterial colonies were used for PCR. The results are shown in Fig. 1, in which lanes 1-9 contained target fragments of $\sim 500 \mathrm{bp}$, which matched the expected fragment size. The PET44a-pla recombinants were double digested using $\mathrm{NdeI}$ and $\mathrm{XhoI}$ (Fig. 2). The sizes of the target fragments were consistent, demonstrating successful construction of the PET44a carrier containing the target gene. The homology between the sequencing results and the original sequences was $100 \%$, therefore, construction of an expressive prokaryote strain may be considered in the future.

Expression and identification of the Pla al protein. As shown in Fig. 3, expression of Pla a1 was observed in the Rosetta strain. The expression of Pla al was observed following $0.5 \mathrm{mmol} / \mathrm{l}$ IPTG (lanes 2-6) compared with the non-induced control (lane 1). The expression of the target protein $(18 \mathrm{kDa})$ was significantly higher in the induced lanes compared with the control, indicating that the exogenous gene expressed the Pla a1 protein. The marker used was an 03-04 protein marker.

Identification of the expressed protein form. Following the induction of protein expression, the bacteria were harvested and non-denaturing lysis buffer was added prior to sonication. The supernatants and precipitates were analyzed by SDS-PAGE. 


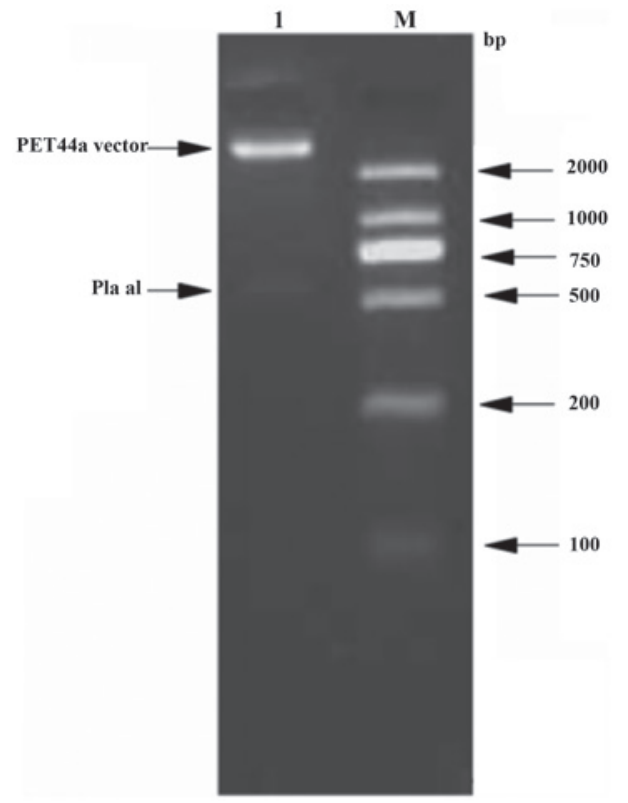

Figure 2. Electrophoresis results of the NdeI and XhoI double digestion products for the PET44a-pla a1 recombinants. 1, product of double digestion; two bands are shown in which the small fragment ( $\sim 500 \mathrm{bp})$ was the target gene fragment and the large fragment was the PET 44a vector. M, DL2000 DNA marker.

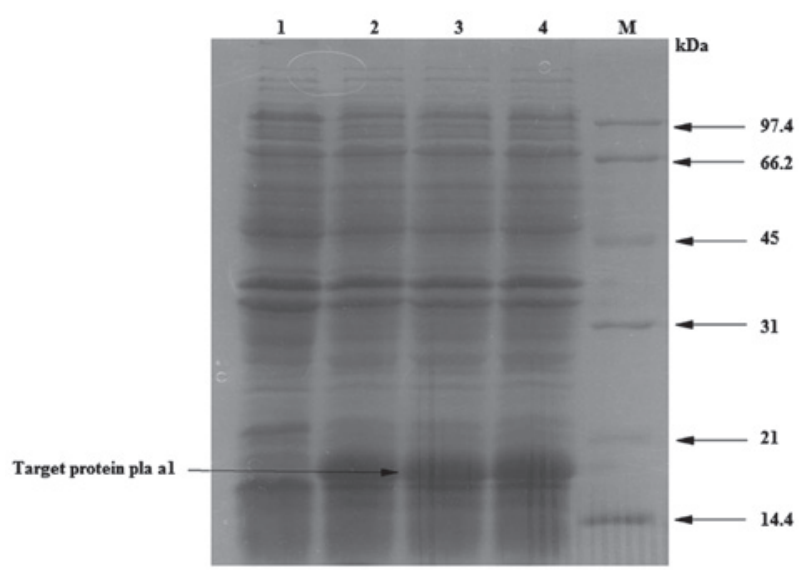

Figure 3. Induced expression of the Pla a1 gene. The expression of the target protein $(18 \mathrm{kDa})$ was significantly higher in the induced lanes compared with the control, indicating that the exogenous gene expressed the Pla a1 protein. 1, non-induced control; 2-4, IPTG induced (repeated); M, 03-04 protein marker. IPTG, isopropyl $\beta$-D-1-thiogalactopyranoside.

As shown in Fig. 4, the predominant inclusion body expression of the target protein was observed in the induction lane (lane 2) compared with the control and sonicated supernatant samples.

Purification of the Pla al fused protein. The supernatents were collected using $1 \mathrm{ml}$ StrepTrap HP prepacked columns. The supernatants $(100 \mu \mathrm{l})$ were added to $20 \mu \mathrm{l} 6 \mathrm{X}$ loading buffer containing $\beta$-mercaptoethanol and boiled for 6 min using the AKTA FPLC system. Following centrifugation at $10,000 \mathrm{rpm}$ for $5 \mathrm{~min}, 10 \mu \mathrm{l}$ supernatant was added to an SDS-PAGE gel. As shown in Fig. 5, the penetration peak was observed in lane 1 , whereas the penetration peak of the

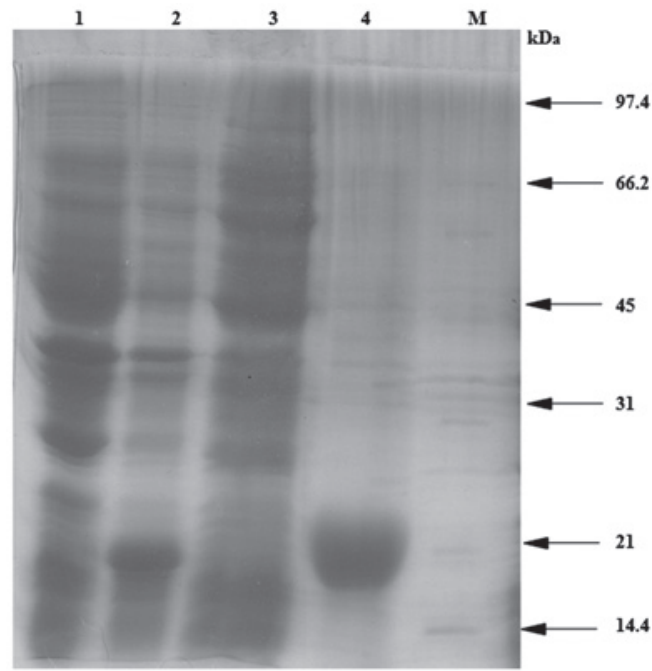

Figure 4. Identification of the expression of recombinant protein. 1, control; 2 , induction; 3 , sonicated supernatant; 4 , sonicated precipitation.

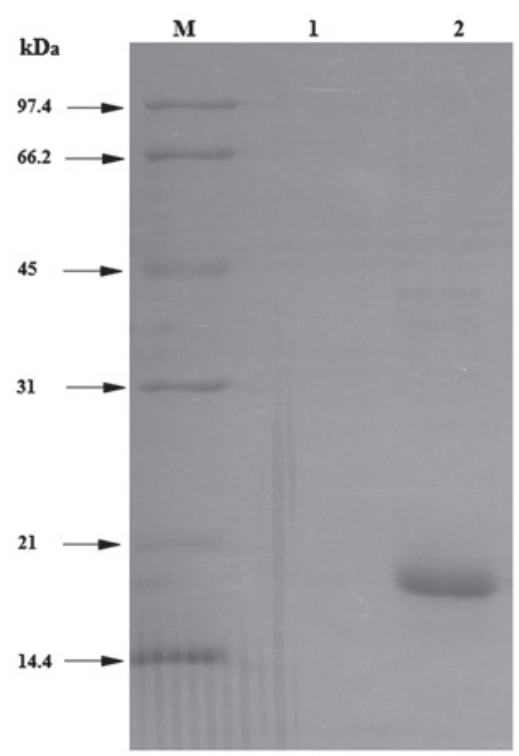

Figure 5. SDS-PAGE identification of the purified recombinant protein. 1, penetration peak; 2 , elution peak of the target protein.

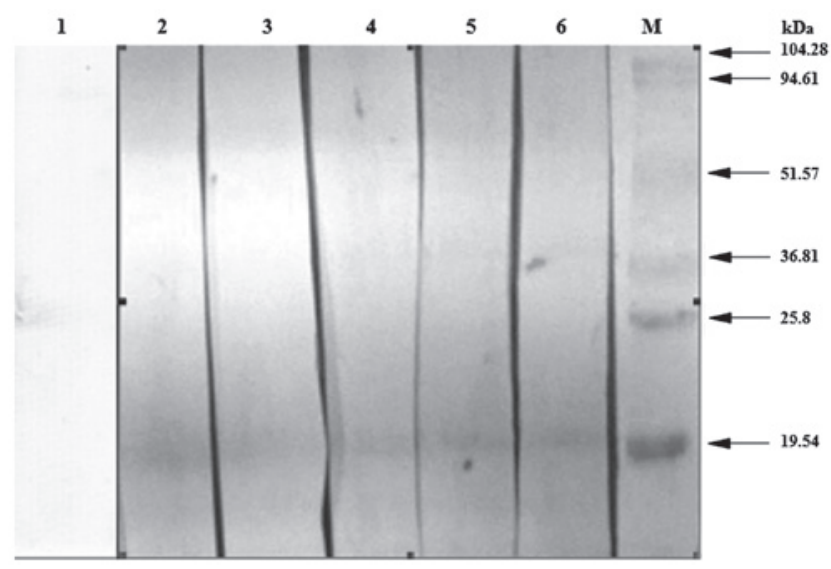

Figure 6. Immunoblotting results of the recombinant protein. 1, normal serum control; 2-6, results of pollen-positive serum immunoblotting, which exhibited a distinct band at the target site, demonstrating that the target protein contained the specific antigen. 
target protein was observed in lane 2 , which was obtained at the UV absorption peak (>50 $\mathrm{mA}$ ) under the protein elution.

Western blot analysis of the purified proteins. The induced, purified proteins were used for western blot analysis and the serum from the patients with Platanus pollen allergy was used as the primary antibody. As shown in Fig. 6, in which lane 1 contained normal serum as a control, the serum in lanes 2-6 were detected by ImmunoCAP and the Platanus pollen allergen-specific immunoglobulin $\mathrm{E}$ antibodies were grade two or above. Lanes 2-6 exhibited a distinct band at the target site, demonstrating that the target protein contained the Platanus pollen allergen-specific immunoglobulin E antibodies.

Sequencing of the purified fusion protein. The purified fusion proteins were transferred onto PVDF membranes for sequencing (Proteome Research Analysis Center of the Institute of Biochemistry and Cell Biology, Shanghai Institutes for Biological Sciences, Chinese Academy of Sciences). The sequencing results were consistent with the predicted gene sequences in GenBank (ID AJ427413.2), which indicated that the synthesized protein was the target protein.

\section{Discussion}

Epidemiological data of pollens in China, Europe and the USA, demonstrate that Platanus pollens are widespread in distribution $(1,2,4,14)$. Previous studies have suggested that Platanus pollen causes a substantial number of cases of hay fever, including allergic asthma, allergic rhinitis and urticaria $(7,12,15-18)$. However, few investigations have focused on the expression, purification and identification of Platanus pollen.

A previous study revealed that the codon bias, mRNA stability, initial efficiency of translation and carrier selection are significant factors affecting the efficiency of exogenous gene expression (19) and investigations into codon bias has become an area of interest. If the target gene does not match the expressive host, this reduces the efficiency and stability of mRNA translation and can result in early termination (20). In the present study. the GC content was increased between 44.3 and $47.6 \%$ through codon optimization. In an initial region of translation, the optimal codons were preferred and the RNA secondary structure was considered to maintain a linear open structure in this region, facilitating protein translation.

The sera was obtained from blood samples from 18 patients with positive Platanus pollen allergen skin tests were obtained. For ImmunoCAP assessment, nine of the cases were in stage two or above. Purification of the exogenous target proteins was performed for western blot analysis and the results revealed five cases with positive reactions, exhibiting positive response rates of $>50 \%$. Immunoblotting identified Platanus pollen as the predominant type of allergen protein and demonstrated that the exogenous recombinant protein had the corresponding antigen.

With the development of molecular biology techniques, recombinant pollen, which is prepared by genetic engineering and is used in the clinical treatment and research of allergic diseases, has became a strategy used in treatment of allergies. Recombinant allergens with high purity and yield are easily standardized and have no exogenous toxic substances or pathogenic microbial contamination (21). In vitro investigations and the results of skin tests have demonstrated that the majority of recombinant gene allergen activity is consistent with that of natural allergens (21). A recombinant plasmid with an allergen-encoding gene requires construction to express the functional activity of the recombinant allergen, which may be applied in the diagnosis and treatment of allergic diseases and be used for detailed investigations of allergen molecular structure and pathogenic mechanisms. The present study provided a basis for subsequent transformations of hypoallergenic allergens and the development of allergen nucleic acid vaccines.

\section{Acknowledgements}

This study was supported by the Key Topics of Health Ministry: The Specific Diagnosis and Immunotherapy of Recombinant Allergen for Bronchial Asthma (no. 2007353), the Major Issue of National Science and Technology (no. 2008ZX08011-005) and Key Projects (no. 2009ZX08011-004B) and Guangzhou Educational System Research and Innovation Academic Team (no. B94118).

\section{References}

1. Kosisky SE, Marks MS and Nelson MR: Pollen aeroallergens in the Washington, DC, metropolitan area: a 10-year volumetric survey (1998-2007). Ann Allergy Asthma Immunol 104: 223-235, 2010.

2. Aira MJ, Rodriguez-Rajo FJ, Fernandez-Gonzalez M and Jato V: Airborne pollen of ornamental tree species in the NW of Spain. Environ Monit Assess 173: 765-775, 2010.

3. Ture $\mathrm{C}$ and Bocuk $\mathrm{H}$ : Analysis of airborne pollen grains in Bilecik, Turkey. Environ Monit Assess 151: 27-35, 2009.

4. Celenk S, Canitez Y, Bicakci A, et al: An aerobiological study on pollen grains in the atmosphere of North-West Turkey. Environ Monit Assess 158: 365-380, 2009.

5. Liu GH, Zhu RF, Zhang W, et al: Survey of airborne pollen in Hubei Province. Chin Med Sci J 23: 212-217, 2008.

6. Lu JM, Sun XZ, Liu Y, et al: Survey of airborne pollen in Xi'an City. Journal of Xi'an Jiaotong University (Medical Science Edition) 31: 472-474, 2010.

7. Lauer I, Miguel-Moncin MS, Abel T, et al: Identification of a plane pollen lipid transfer protein (Pla a 3) and its immunological relation to the peach lipid-transfer protein, Pru p 3. Clin Exp Allergy 37: 261-269, 2007.

8. Alcázar P, García-Mozo H, Trigo Mdel M, et al: Platanus pollen season in Andalusia (southern Spain): trends and modeling. J Environ Monit 13: 2502-2510, 2011.

9. Mardones P, Grau M, Araya J, et al: First annual register of allergenic pollen in Talca, Chile. Allergol Immunopathol (Madr) 41: 233-238, 2012.

10. Pérez-Badia R, Rapp A, Vaquero C and Fernández-González F: Aerobiological study in east-central Iberian Peninsula: pollen diversity and dynamics for major taxa. Ann Agric Environ Med 18: 99-111, 2011.

11. Asturias JA, Ibarrols I, Eraso E, et al: The major Platanus acerifolia pollen allergen Pla a1 has sequence homology to invertase inhibitors. Clin Exp Allergy 33: 978-985, 2003.

12. Ibarrola I, Arilla MC, Martinez A, et al: Identification of a polygalacturonase as a major allergen (Pla a2) from Platanus acerifolia pollen. J Allergy Clin Immunol 113: 1185-1191, 2004.

13. Laemmli UK: Cleavage of structural proteins during the assembly of the head of bacteriophage T4. Nature 227: 680-685, 1970.

14. Celenk S, Bicakci A, Tamay Z, et al: Airborne pollen in European and Asian parts of Istanbul. Environ Monit Assess 164: 391-402, 2009.

15. Subiza J, Cabrera M, Valdivieso R, et al: Seasonal asthma caused by airborne Platanus pollen. Clin Exp Allergy 24: 1123-1129, 1994. 
16. Pazouki N, Sankian M, Leung PT, et al: Identification of cyclophilin as a novel allergen from Platanus orientalis pollens by mass spectrometry. J Biosci Bioeng 107: 215-217, 2009.

17. Fernández-GonzálezD, González-ParradoZ, Vega-Maray AM, et al: Platanus pollen allergen, Pla a 1: quantification in the atmosphere and influence on a sensitizing population. Clin Exp Allergy 40: 1701-1708, 2010.

18. Varela S, Subiza J, Subiza JL, et al: Platanus pollen as an important cause of pollinosis. J Allergy Clin Immunol 100: 748-754, 1997.
19. Baneyx F: Recombinant protein expression in Escherichia coli. Curr Opin Biotechnol 10: 411-421, 1999.

20. Zheng BQ: Escherichia coli codon preference overview. Silicon Valley 3: 24, 2009.

21. Nikolaizik WH, Weichel M, Blaser K and Crameri R: Intracutaneous tests with recombinant allergens in cystic fibrosis patients with allergic bronchopulmonary aspergillosis and Aspergillus allergy. Am J Respir Crit Care Med 165: 916-921, 2002. 